\title{
Promoting Historical Thinking in Schools through Low Fidelity, Low-Cost, Easily Reproduceable, Tangible and Embodied Interactions
}

\author{
https://doi.org/10.3991/ijet.v13i12.8728 \\ Stergios Kalpakis, George Palaigeorgiou $\left.{ }^{\bowtie}\right)$, Kostas Kasvikis \\ University of Western Macedonia, Florina, Greece \\ gpalegeo@gmail.com
}

\begin{abstract}
Many ubiquitous technologies, such as augmented and virtual reality, virtual field trips, tangible environments and interactive installations are continuously being examined for learning about history. All these approaches strive to offer an interactive, explorative, authentic, and exact regeneration of the past and, they are demanding both in regards to their cost and to their development requirements; hence, they are far from accessible in school contexts. In this study, we will examine, whether interactive low-fidelity low-cost approximations of the real objects, and conditions of the past, together with whole-body interactions may enable historical understanding in a playful manner. To evaluate this claim, sixty-six (66) students of 6th grade played with an interactive environment with the characteristics mentioned, in twenty (20) groups. Afterwards, students were asked to complete a questionnaire assessing their historical understanding and their experience. Additionally, all groups participated in brief group interviews. Students were very positive towards the environment and considered it as enjoyable, intriguing and effective. They claimed that it is preferable to both traditional ways of classroom learning and learning devices like tablets and mobiles. According to our results, the requirements for seamless authenticity may not apply for primary school students and this conclusion opens up a lot of opportunities for moving away from traditional means of learning about history.
\end{abstract}

Keywords - historical thinking, learning about history, mixed reality environments, embodied interactions, whole-body interactions

\section{Introduction}

History education gives students an opportunity to search, learn and understand about the past and to make connections with the present in order to become responsible, reflective, and active citizens. History education also provides students with information and critical thinking skills that they can use to develop social understanding and make informed decisions about their personal and social life [1-3]. However, most students consider History as a boring lesson that requires the memorization of information such as names, dates and events. Recently, historical learning has moved from knowing facts, names, dates, and events, to the concept of "historical understanding", which in 
turn involves learning historical content, applying research methods, analyzing and evaluating resources, and reaching conclusions by critically reading historical sources of information [4],[5]. Students are encouraged not just to remember facts, but to familiarize themselves with the way historians work: they are asked to construct their own, subjective, meaning about what the sources "are telling" them.

Several studies have suggested that the use of ICT may motivate students and help them develop historical thinking. The integration of ICT in history teaching in many cases seems to enhance historical understanding [6], contribute to the transformation of history learning to an explorative and critical approach to the past rather than a passive accumulation of information [7-9], but also to increase the interest, concentration and enjoyable feelings of students during the learning process [10-12]. ICT seems to offer a lot of affordances that address history teaching needs, such as the use of video documentaries, the exploitation of the web for seeking historical sources and information, the utilization of Web 2.0 technology for collaborative historical research, etc. [1],[2],[10].

Many ubiquitous technologies, such as augmented and virtual reality, virtual field trips and tangible or mixed reality installations are continuously being examined in the history learning context. Museums and other heritage institutions, especially, are increasingly augmenting their spaces with highly interactive technologies. While they have traditionally exploited the use of physical artifacts to provide their visitors with an experience of authenticity by simply displaying them as mere objects [13], now they seek ways to increase their interactivity with their visitors to make the learning experience engaging, effective and joyful. Nevertheless, museum interactive installations are usually expensive, strive for authenticity, preciseness and elegance, are designed and developed by expert teams and are far from accessible in school contexts. In this study we will examine, whether low-cost, low-fidelity, easily reconstructable tangible and embodied interactions in a mixed reality environment about history may also enhance students' engagement and historical understanding. The aim is to bring closer the classroom, the interactive installations for history and the maker culture.

\section{Learning about history with ICT}

Teaching history with ICT has several different roots. For example, searching on huge historical databases for sources gives students the opportunity to work as historians and answer historical questions they pose. Microsoft PowerPoint, short filmmaking programs [14] and interactive maps [15],[16] have also been studied as innovative means for students to present the results of their research. Historical video games have also grabbed great traction. Video games represent the past in an impressive way and place the student in the position of historical persons, inviting him to make decisions and to understand the causes and effects of historical events [17],[18]. Students can play with various historical situations "first-hand" and by applying problem-solving skills while usually immersed in a particular geographical frame. Virtual Museums are also a trend in learning about history with ICT. Virtual history museums are a blend of digital storytelling and online simulation [19]. There are several simulations on large 
surfaces or through virtual reality devices which depict antiquities and monuments in their original form and present everyday life in the past or important historical events, giving the student the ability to navigate in a virtual monument [20] and join the story, interact with people of the past, to take roles and make decisions, usually with the help of position and motion sensors [6], [7], [21]. In such occasions, students can spend a lot of time exploring the boundless contents of the ever-expanding virtual history museums from the comfort of their own school or home [19]. Lately, there is a new trend on examining digital heritage through the affordances of augmented reality (AR) and virtual reality (VR) [22-24]. For example, students can visit historical places, and with the help of their mobiles, they can see information or depictions of buildings and frescoes that no longer exist [25],[26].

Historical learning and understanding in museums are usually based on physical artifacts to provide visitors with an experience of authenticity and elicit empathy with historical events. Interacting with historical objects is "a necessary condition for the generation of knowledge" [27] since they offer an inherent narrativity about how they were used by people at a certain time [28]. When the artifacts become interactive with the help of digital technologies, they seem to intrigue almost every visitor [29] while they evoke a sense of cultural presence. Touching artifacts promote learners to reflect on cultural aspects or related practices. The resulting empathy and emotional engagement seem to stimulate younger's historical understanding [30] although other studies propose that this kind of engagement does not often lead to the desired learning results [31]. Such approaches are closer to student's interactive experiences and expectations, usually gamify learning and exploit embodied learning affordances in order to achieve efficient, effective, and enjoyable learning [32].

Recent developments in tangible interactions have highlighted possibilities for connecting the intangible with the tangible cultural heritage, for offering a 'multimodal' engagement with the past [33]. Tangible interactions aren't widespread while their real contribution is unclear. There is scarce research in embodied history learning, and it is unexpected that we know so little about interactive experiences in museums although most times they are tangible and embodied [34]. New embodied interaction technologies have already been studied for performing physical actions that serve as "conceptual leverage" [35] in several domains such as physics or math. Full-body interaction has the potential to support learning by involving users at different levels such as sensorimotor experience, cognitive aspects, and affective factors; the physical world seems to underpin one's internal mental representations [36]. The design rationale is that having learners act out and physicalize the systems processes, relationships, etc., will create conceptual anchors from which new knowledge can be built [35]. The new environments seem to increase learner engagement since body-based experiences are more perceptually immersive and learners may feel that they are in a more authentic and meaningful educational space [37]. There are two types of environments which seem to promote embodied learning, tangibles and mixed reality environments. Mixed Reality (MR) environments merge the digital with the physical, offer a vivid and immersive audiovisual interface for eliciting body activity and allow students to become part of the system they are trying to familiarize with [38]. Tangibles are able to offer a natural and immediate form of interaction that is accessible to learners. They promote active 
and hands-on engagement, allow for exploration, expression, discovery and reflection, provide learners with 'tools to think with' and offer opportunities for collaborative activity among learners [39].

\section{Low cost, low fidelity interactive historical exhibitions}

There are two main complications when seeking ways to transfer embodied interactive installations to school contexts for exploiting their learning value. Firstly, as [40] claims for virtual heritage, most interactive historical exhibitions should strive to carefully capture objects and processes, to present information as accurately, authentically, and engagingly as possible, to provide an effective and inspirational learning environment which may allow the possibility of participating in its construction. Hence, the use of ICT should contribute to the faithful representation of the past, the exact regeneration of the past conditions, events and actions, and that requires a lot of people, money and resources. Secondly, most existing embodied interaction environments are usually developed for research purposes, they are created with expensive technologies and do to aim to be reproducible at scale.

While these problems seem challenging, they coincide with the recent enthusiasm for the "maker movement" [41]. Low-cost rapid prototyping together with the uprising trend of arts and crafts fairs, tinkering and inventing, can enable students to recreate such embodied interactive technologies and, concurrently, empower creativity and problem solving, brainstorming, sustained perseverance and a lot more [42-44]. Recently, following this trend, Triantafyllidou et al. [32] proposed a low-cost augmented 3D tangible model of a historical site, in which students could interact critically with historical content through a virtual field trip by using their fingers. Their study concluded that FingerTrips enhanced students' engagement and motivation in history learning and made them feel as active participants in the historical event presented.

In this manuscript, we propose an alternative way of using mixed reality environments to represent historical information. The noticeable difference lies in the fact that we are not aiming at the faithful representation of historical events, places or phenomena, but in representations that

- are low fidelity approximations of the real objects and conditions,

- function metaphorically and present abstract concepts as concrete instances,

- use the interaction space as a semiotic resource,

- elicit whole-body interactions,

- enable historical understanding in a playful manner,

- are low cost constructions,

- are easily reconstructable and reprogrammable even by primary school students.

We aim to provide an affordable level of embodied interactions, representations, actions and feedback which will enthuse students, provide useful guidance and contribute to their historical understanding. Such environments should even allow learners to create their own versions of interactions and learning content. 


\section{$4 \quad$ Learning environment and interaction types}

In order to evaluate our proposal, we create a mixed reality environment focused on modern European history. The subject is a module of the school history book, taught in the sixth grade of Greek schools, entitled "Developments in Europe in the Modern Times (mid-15th century - early 19th century)", divided into three chapters. The contents of the three chapters were transformed into a single historical narrative.

The environment was installed in two adjacent walls of a small dark room of $3 \times 4$ meters. On the first surface, there were activities for the period of the Renaissance and the Great Discovers, and on the second surface, there were interactions about the period of Enlightenment and the French Revolution. The students followed a guided exploration of the environment which evolved according to the time of the historical events. In each historical period, students had to interact with the physical objects and their augmentations, to discover all necessary information, to understand historical events and, to develop their historical thinking. There was a continuous interplay between visual, acoustic and tangible stimuli.

The mixed reality environment with its physical objects functioned as a semi-finished interactive canvas which predisposed students on what may follow, and, concurrently, reminded them of what preceded, without however revealing the details of each interactive episode all the time. The learning environment worked as a tangible timeline since it moved students' focus from objects and representations of one period to another. Although metaphorical relations are considered as useful and productive in tangible and embodied interaction research, little is known about how to identify such relations, or how to transform them effectively into interaction models for each domain [45]. The proposed mixed reality environment provided four types of interactions: narrative interfaces, low fidelity historical objects, embodied metaphors and conceptual object metaphors. Examples of similar interfaces are presented below.

\subsection{Narrative interfaces}

Storytelling is one of the more effective means of teaching history in the classroom. In this category, we refer to tangible interfaces that trigger a brief narration, necessary to introduce or to set the ideological framework of a historical period, for example, the periods of Renaissance and Enlightenment.

As depicted in fig. 1A, Leonardo da Vinci's self-portrait, was used as a storytelling interface for the introduction to the Renaissance period. As soon as the student touched the blinking loudspeaker, Leonardo da Vinci's face came alive and narrated a short description. Students had to control the pace of the narration by clicking the loudspeaker a couple of times. Similarly, for the introduction to the activities concerning the Enlightenment period, students were asked to touch a blinking arrow and afterward a "turned on the light" switch, as shown in fig. 1B. The switch was connected with the conception of an idea. When clicked, the interior of a contoured design "illuminated" the figure of an Enlightenment philosopher, who set out his views. When each of the Enlighteners completed his narrative, the bright arrow was blinking again and called the students to listen to the next Enlightener. 

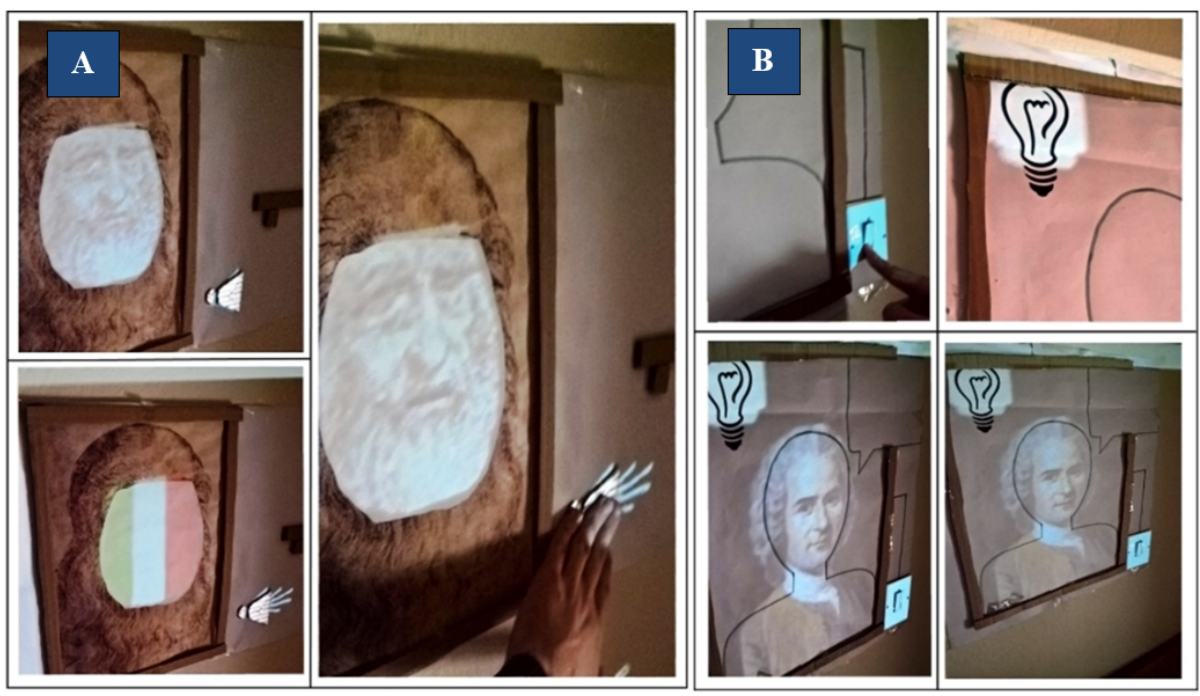

Fig. 1. Narrative interfaces

\subsection{Low fidelity historical objects}

Low fidelity augmented objects mimic historical concepts and objects. We used similar interfaces for the invention of typography and the French Revolution. For example, for introducing the invention of typography, we constructed a low fidelity model of a printing press. As soon as students pushed the plunger, a page appeared from the Gutenberg Bible. As shown in the fig. 2A, when the user completed five reps, the print was completed, and the book was "placed" in the library. Likewise, the French Revolution was initiated through an augmented cannon and a stack of shells at the height of the Bastille fortress. A light focused on the cannon called students to "arm" and "fire" it, and as a result glow and smoke appeared, a cannonade was heard and the revolts started to shout.

\subsection{Conceptual objects}

Conceptual objects are manipulatives which help an idea or an activity to be understood in terms of a physical related object. For example, at a Latin American site, in a 16 th century world map, the miniature of tomato was pinned. As soon as the student touched a real tomato to the miniature, a virtual arrow pointing towards Europe appeared, thus representing the process of introducing ever-unknown products from the New World. In the same way, as soon as the students touched the embossed representation of gold on a $16^{\text {th }}$-century gravure depicting native work in a mine in Peru, an arrow pointing towards Europe also appeared, and at the same time, virtual rods filled a chart of Gold imports into Spain in the 16th century. Also, there was a sketch from the late 18 th century depicting the social stratification in the pre-revolutionary France. A luminous sign urged the students to click the tool held by the representative of the 
lower social class. Immediately after, the social pyramid of the French society was projected to depict the social causes that led to the French Revolution. The same class was moved up to the top of the table with the fall of Bastille.

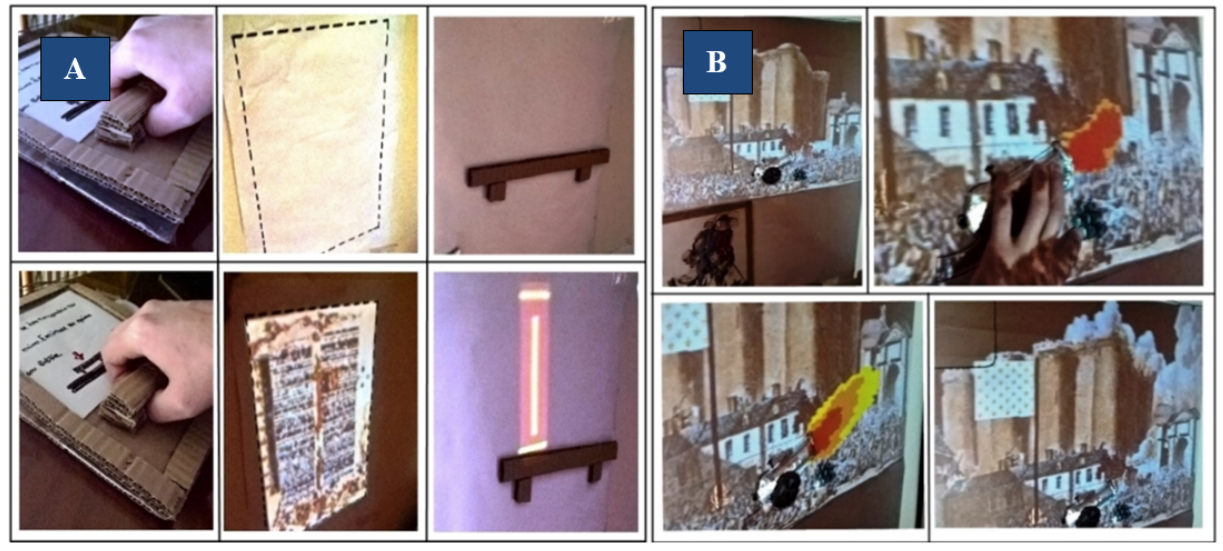

Fig. 2. Low fidelity historical prototypes

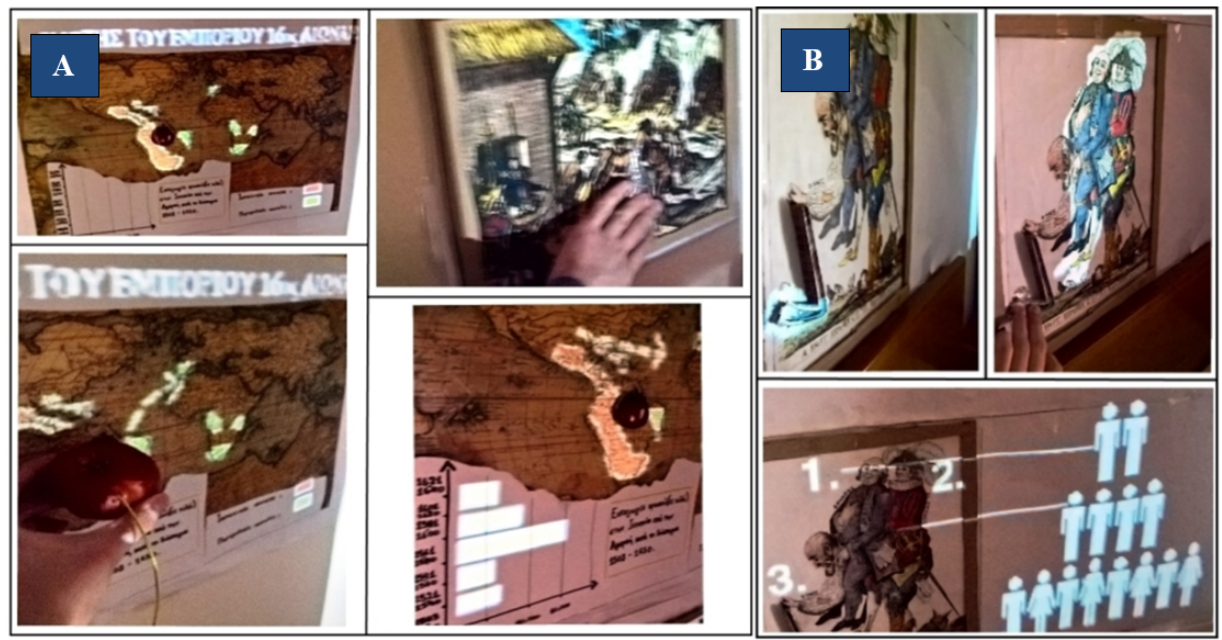

Fig. 3. Conceptual objects

\subsection{Embodied metaphors}

Embodied metaphors may enable children to explore and reason about abstract concepts [45]. We exploited embodied metaphors in our installment for the design of the Vitruvius Man. The Vitruvius Man was projected on the surface of the wall, while on the floor there were two pairs of human steps. Da Vinci called on the students to "help" him to complete his drawing, and the students had to quickly jump between the two pairs of footprints while the Vitruvius Man replicated their behavior. That was repeated 
until the drawing was completed. Students, with their embodied action, joined themselves in the drawing.
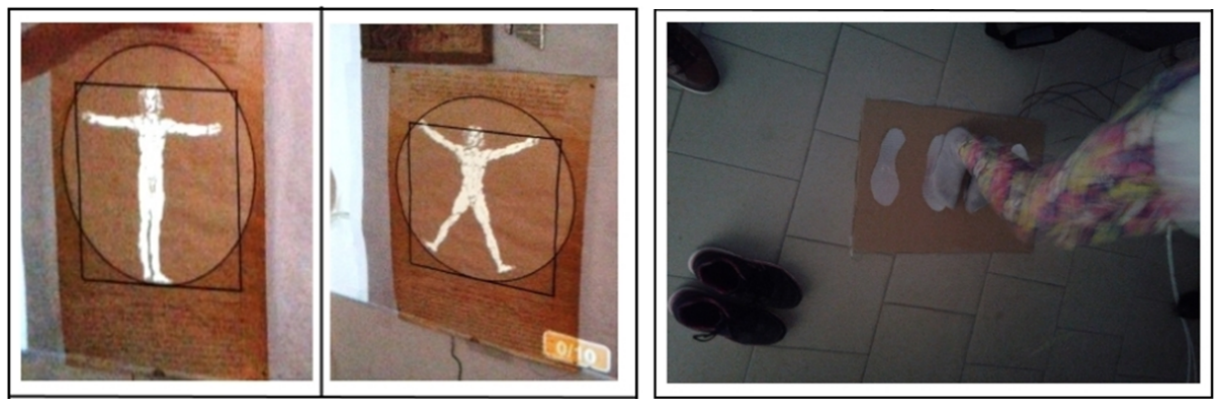

Fig. 4. Embodied metaphors

\subsection{Learning Environment Settings}

Students' interactions on the walls and the footpad were supported by two Makey Makey prototyping boards, whose inputs were embedded into the various objects of the mixed reality environment. Two computers and two projectors were needed. The augmentations and the interactions were programmed with MIT's Scratch which is a programming environment that can be exploited even by primary school students. That way, students can take control over the proposed setting, they can reprogram it to address their perception, interests, and views, they can take the ownership of the historical experience or even create their versions of other historical periods. The proposed model is open sourced and constructed of low-cost material and components.

\section{$5 \quad$ Research Methodology}

To evaluate the proposed environment, sixty-six (66) students of 6th grade from seven schools, 34 boys and 32 girls participated in a study. The participants played with the environment in twenty 20 groups and groups of 3 or 4 students. Each session lasted about 20 minutes. Students didn't have been taught the domain under examination.

At the beginning of the game, brief instructions were given to each group, to help students become familiar with the concept of interacting with the various interfaces. The narration evolved in the order of historical events. The researchers offered guidance whenever the participants requested for it. At the end of each session, students were asked to complete an open-ended questionnaire for assessing their historical understanding and a short closed-type questionnaire about the easiness the enjoyment and the effectiveness of the environment. All 20 groups participated immediately after in brief group interview in a separate, quieter place.

The questionnaire assessing the historical understanding of the students consisted of four open-ended questions for the four historical periods. In history, unlike science, it is necessary to take into account the multiplicity of answers that can be given to a 
question in order to draw conclusions about the level of historical thinking. Thus, the questions were general and abstract and let students describe their historical understanding (e.g., Which were the basic ideas of Enlightenment?). The attitudes questionnaire consisted of 9 5-point Likert questions and aimed at identifying whether the environment was easy to use, was effective and efficient and whether it was preferable in comparison to traditional ways of learning about history. Finally, the short interview aimed at letting students express their experience evaluation in their own words and underline the important elements of the interactions through their perspective (e.g., Did the setting helped you to learn about the history? Would you like to learn about history this way? etc.).

Open-ended historical questions were analyzed separately by two of the researchers who specialized in history instruction and were grouped into four categories of historical understanding. Cohen's Kappa was calculated to determine inter-rater reliability for each question and their agreement was more than 0.8 which is considered acceptable. Afterwards, the levels of historical understanding were quantified to levels 0 to 3 , with greater numbers showing deeper understanding $(0$ - no answer, 1 - at least one perspective is written, 2- at least two perspectives are identified, 3-complex answers). All audio-recorded interviews were transcribed and then encoded and compared within and between cases. Finally, the three researchers collaborated to reach consensus on the commonly identified issues.

\section{$6 \quad$ Results}

\subsection{Historical understanding}

Students performance can be considered positive, taking into account the constraints of the available time and the context of the study. As shown in Table 1, students demonstrated adequate performance in the first question concerning the occupations of people during the Renaissance, the second question concerning the distinction between the positive and negative results of the New World Discovery, and the fourth question about the causes of the French Revolution. Students did not give satisfactory answers regarding the ideological framework of the Enlightenment's movement.

In Table 1, we present the type of interfaces used for interacting with the historical content. If we try to correlate these types of interfaces with students' performance, it seems that the activities that involved more embodied actions had a more positive impact on historical understanding than the other activities. For example, questions 1,2,4 involved the interaction with interfaces like Embodied Metaphors, Low fidelity historical objects, Conceptual objects which require to touch, act on, embody and dramatize historical content. In opposition, the third question involves only narrative interfaces, and while they might have been unexpected and challenging, their effectiveness was not adequate. 
Table 1. Students' historical thinking

\begin{tabular}{|l|l|c|c|}
\hline \multicolumn{1}{|c|}{ Question } & \multicolumn{1}{|c|}{ Content introduced with } & Average & SD \\
\hline $\begin{array}{l}\text { 1.What were the occupations and interests of } \\
\text { people at the time of the Renaissance }\end{array}$ & $\begin{array}{l}\text { Narrative Interfaces, Embodied } \\
\text { Metaphors, Low fidelity historical } \\
\text { objects }\end{array}$ & 1.53 & 0.95 \\
\hline $\begin{array}{l}\text { 2.What was the most positive and most nega- } \\
\text { tive result of New World Discovery? }\end{array}$ & Conceptual objects & 1.76 & 0.81 \\
\hline 3.What were the basic ideas of Enlightenment? & Narrative Interfaces & 0.95 & 1.07 \\
\hline $\begin{array}{l}\text { 4. What were the reasons that led to the French } \\
\text { Revolution of 1789? }\end{array}$ & $\begin{array}{l}\text { Low fidelity historical objects, Con- } \\
\text { ceptual objects }\end{array}$ & 1.47 & 1.12 \\
\hline
\end{tabular}

\subsection{Students attitudes}

As shown in Table 2, students evaluated the learning environment as innovative, very enjoyable and easy to use. They also claimed that this setting helped them to learn faster in comparison to the typical school environment and that they prefer this learning approach.

Table 2. Students' historical thinking

\begin{tabular}{|l|c|c|}
\hline \multicolumn{1}{|c|}{ Question } & Average & SD \\
\hline The tangible interface is pleasant to use and I enjoyed interacting with it. & 4.62 & .72 \\
\hline The tangible interface helps me learn faster. & 4.44 & .75 \\
\hline The use of the interface was difficult. & 1.91 & 1.19 \\
\hline $\begin{array}{l}\text { The interface provides an easy way of learning that is difficult to achieve in the class- } \\
\text { room with the traditional media. }\end{array}$ & 3.99 & 1.14 \\
\hline $\begin{array}{l}\text { The interface allows me to make mistakes and gives appropriate feedback to correct } \\
\text { them }\end{array}$ & 3.86 & 1.20 \\
\hline I prefer the traditional way of learning, I learn better that way & 2.07 & 1.18 \\
\hline The interface is innovative, I have not seen anything like this in the past. & 4.06 & 1.02 \\
\hline I want my teachers to deliver similar interfaces for learning purposes & 4.29 & 1.03 \\
\hline I would like to be able to create similar interfaces by myself & 4.12 & 1.03 \\
\hline
\end{tabular}

It is of special importance that students expressed their will to be able to create similar learning environments and also claimed that they would like their teachers to provide them with similar interfaces and experiences. These attitudes strengthen our hypothesis that such environments could be integrated into the school environment with either students or teachers as their designers and constructors.

\subsection{Students interviews}

Students reinforced the quantitative observations in the interviews. The majority of the them stated that they considered the environment easy to use, joyful and intriguing and that they would like to work more often with similar environments. The low fidelity interactive installation enhanced students' engagement and motivated them to learn 
more. Additionally, students considered that the interactive, playful and multimedia character of the setting improved their concentration levels.

"It helped us because it was fun and we were interested in."

"It was a lot easier to learn than reading the book."

"It's more practical, and there's not so much left when reading a book."

"In class, we are talking a lot between us, here we had to be focused, and so we learned."

Despite the sketchy objects and constructions, students commented that the environment was authentic, vivid and realistic. They also underlined that while involved in the various activities, they felt like they were interacting with the protagonists of the historical events; they felt part of the historical process, they thought that they were the ones who created history. At the same time, the brief presentation of the historical events of a long period, without extensive narratives and by using multimedia and multimodal interactions, allowed them to get a fast and useful overall understanding:

"It [the environment] helped us because the people who created history were telling us what they did."

"It helped us because it was like you were in the French Revolution."

"It does it more quickly and with more success."

Students were excited with the hands-on interaction with the physical objects, the representation of the abstract concepts as concrete instances and the operationalization of metaphorical actions. They repeatedly underlined that the most impressive aspect of their experience was the embossed surface and the tangible perspectives of the environment which transformed history learning to a process of interacting with everyday objects.

"we liked most that we touched [real objects] and learning became more entertaining."

"[we liked most that] it is three-dimensional and you touch it."

"[we liked most that] the learning environment is embossed."

"You feel it [the learning environment]."

"Here, you touch papers and in general everyday objects [when learning about history]."

The environment required students not to sit behind a desk in order to learn about history but to participate actively with their body in the various activities. This was not expected and not repeated in the past. The interactive installation responded to their actions and guided them by using unanticipated augmentations which fascinated the students and made them feel ownership of the learning process.

"You move in the room; you do not just sit in a chair so as to learn history."

"It's very alive, you touch it and it responds right away."

"It is here in front of us and we control it with our hands."

Interestingly, most of the students differentiated the mixed reality environment from other technologies like tablets or electronic games which belong to their much-appreciated everyday informational ecology. They claimed that the proposed setting is 
superior for history learning since the interactions are natural, tangible and embodied and more intense than tapping on a screen.

"It's different from online games because you use your hands and your body to play."

"Here you interact with it with your hands and not with the keyboard."

"There is a big surface here and you grab the objects, you do not just touch them."

"It's more real because you do not just tap on a screen but on things."

Students' references to the crafted nature of the environment were of special interest. Not only the low fidelity interfaces did not degrade the quality of the experience, but students were excited that they were using easy to create hand-made interfaces with high interactivity.

"I like that that you can make all of these by yourself and can also do even more beautiful things."

"[I was impressed] that you made it."

\section{Discussion}

Interactive installations about history are common place in museums but are difficult to meet at schools since they are demanding both in regards to the cost and accessibility of the required equipment and to the design and development requirements. In this manuscript, we explored the design of low cost, school-friendly interactive installations for history learning. We tried to marry the physical and the digital worlds with simple, affordable tools and enable a multisensory, embodied, and tangible experience' which would promote historical understanding in a playful manner. The mixed reality environment functioned as a semiotic resource, a semi-completed canvas which supported four different learning interaction patterns: narrative interfaces, low fidelity historical objects, conceptual objects, embodied metaphors. Students were called not just to look and listen at an inspiring narration but to be physically active, to control and interact with the narration protagonists, to enact history evolution, to understand the historical space and to "grab" related concepts and objects.

Students considered the proposed environment as enjoyable, intriguing and effective. They claimed that it is preferable to both traditional ways of classroom learning and technological learning devices like tablets and mobiles. Students want to leave the desks, to touch and interact with historical content with new, more experiential and exploratory ways. Students' toy world is not full of preciseness and authenticity; in opposition, students use, play and enjoy with replicas, miniatures, hand-crafted objects and games. As Bailey [46] suggests, miniatures "manipulate reality" through abstraction and compression. Children feel an intimate relation with miniatures since they are like their toys at home with which they are creating and performing narratives almost every day. Reality is not a neutral space but a context being understood based on social and symbolic codes. Hence, according to our results, the requirements for seamless authenticity when creating tangible interactive environments for history learning may not apply for primary school students. This conclusion opens up a lot of opportunities for moving away from traditional means of learning about history. More focus can be 
directed to offering enacted and meaningful experiences with low-cost low fidelity exploratory digital installations.

More details studies have to be done to get insights about the mechanisms of connecting historical understanding with embodied interactions and low fidelity interfaces. Further research is also required for researchers to identify design guidelines for creating a variety of successful historical embodied interaction styles while the minimum and maximum desirable duration of similar activities must be explored. The most prominent question to be answered is whether students are willing to create from scratch similar environments or to transform existing ones. Can the "maker culture" motivate students to design and develop their own crafted interactive installations for learning about history?

\section{References}

[1] Adesote, S. A., \& Fatoki, O. R. (2013). The role of ICT in the teaching and learning of history in the 21st century. Educational Research and Reviews, 8(21): 21-55

[2] Giannopoulos, D. (2015). Italian Presence in the Dodecanese 1912-1943: Teaching a History Topic in Weebly Environment. Procedia Computer Science, 65: 176-181 https://doi.org/10.1016/j.procs.2015.09.106

[3] Yilmaz, K. (2008). A vision of history teaching and learning: Thoughts on history ed-ucation in secondary schools. The High School Journal, 92(2): 37-46 https://doi.org/10.1353/ $\underline{\text { hsj. } 0.0017}$

[4] Peck, C., \& Seixas, P. (2008). Benchmarks of historical thinking: First steps. Canadian Journal of Education, 31(4), 1015.

[5] Seixas, P., Morton, T., Colyer, J., \& Fornazzari, S. (2013). The big six: Historical think-ing concepts. Nelson Education.

[6] Bogdanovych, A., Ijaz, K., \& Simoff, S. (2012, September). The city of uruk: teaching ancient history in a virtual world. In International Conference on Intelligent Virtual Agents (pp. 28-35). Springer, Berlin, Heidelberg. https://doi.org/10.1007/978-3-642-33197-8 3

[7] Blanco-Fernández, Y., López-Nores, M., Pazos-Arias, J. J., Gil-Solla, A., Ramos-Cabrer, M., \& García-Duque, J. (2014). REENACT: A step forward in immersive learn-ing about Human History by augmented reality, role playing and social networking. Expert Systems with Applications, 41(10), 4811-4828. https://doi.org/10.1016/j.eswa.2014.02.018

[8] Waring, S., \& Bentley, C. C. (2012). Constructing historical profiles with digital na-tives. Contemporary Issues in Technology and Teacher Education, 12(2), 184-208.

[9] Wake, J.D. and Wasson, B., 2011, October. Supporting creativity in teaching and learning of history through small-group production of mobile, location-based games. In mLearn2011 conference proceedings (p. 181).

[10] Boadu, G., Awuah, M., Ababio, A.M., \& Eduaquah, S. (2014). An examination of the use of technology in the teaching of history. A study of selected senior high schools in the cape coast metropolis, Ghana. International Journal of Learning, Teaching and Educational Research, 8(1).

[11] Godfrey, R., \& Waddingham, M. (2013). Computer strategy games in the Key Stage 2 History. Education 3-13, 41(1), 39-46. https://doi.org/10.1080/03004279.2012.710098

[12] BakarNordin, A., \& Alias, N. (2013). Learning outcomes and student perceptions in using of blended learning in history. Procedia-Social and Behavioral Sciences, 103, 577-585. https://doi.org/10.1016/j.sbspro.2013.10.375 
Paper-Promoting Historical Thinking in Schools through Low Fidelity, Low-Cost, Easily Reproducea...

[13] Savenije, G. M., \& de Bruijn, P. (2017). Historical empathy in a museum: uniting con-textualisation and emotional engagement. International Journal of Heritage Studies, 1-14. https://doi.org/10.1080/13527258.2017.1339108

[14] Elaggoune, A. (2015). Integrating the Content-based Instruction into the American Civilization Class. Arab World English Journal.

[15] Lambrinos, N., \& Asiklari, F. (2014). The introduction of GIS and GPS through local history teaching in primary school. European Journal of Geography, 5(1), 32-47.

[16] García-Pe-alvo, F. J., Zangrando, V., Seoane Pardo, A. M., Holgado, A. G., \& Ovide, E. (2011). Learning European history and geography in a multicultural and ICT perspec-tive. International Journal of Technology Enhanced Learning, 3(4), 343-354. https://doi.org/10.1504/IJTEL.2011.041278

[17] McCall, J. (2016). Teaching history with digital historical games: An introduction to the field and best practices. Simulation \& Gaming, 47(4), 517-542. https://doi.org/10.1177/ 1046878116646693

[18] Kapell, M. W., \& Elliott, A. B. (Eds.). (2013). Playing with the past: Digital games and the simulation of history. Bloomsbury Publishing USA.

[19] Fork, R. (2017). Technological Resources in the History Classroom. Learning to Teach, 5(1). Retrieved from http://utdr.utoledo.edu/learningtoteach/vol5/iss1/9

[20] Antonaci, A., Ott, M., \& Pozzi, F. (2013). Virtual museums, cultural heritage education and 21st century skills. Learning \& Teaching with Media \& Technology, 185.

[21] Vosinakis, S., \& Avradinis, N. (2016). Virtual Agora: representation of an ancient Greek Agora in virtual worlds using biologically-inspired motivational agents. Medi-terranean Archaeology \& Archaeometry, 16(5).

[22] Yoon, S. A., Elinich, K., Wang, J., Steinmeier, C., \& Tucker, S. (2012). Using augment-ed reality and knowledge-building scaffolds to improve learning in a science museum. International Journal of Computer-Supported Collaborative Learning, 7(4), 519-541. https://doi.org/10.1007/s11412-012-9156-x

[23] Petrelli, D., Ciolfi, L., van Dijk, D., Hornecker, E., Not, E., \& Schmidt, A. (2013). Integrating material and digital: a new way for cultural heritage. interactions, 20(4), 58-63. https://doi.org/10.1145/2486227.2486239

[24] Martina, A., Bottino, A., Rubino, I., \& Cook, D. (2015). One day at The Sands: Explor-ing Las Vegas' intangible heritage through virtual reality. International Journal of Her-itage in the Digital Era, 4(1), 1-19. https://doi.org/10.1260/2047-4970.4.1.1

[25] Kysela, J., \& Štorková, P. (2015). Using augmented reality as a medium for teaching history and tourism. Procedia-Social and behavioral sciences, 174, 926-931. https://doi.org/10.1016/j.sbspro.2015.01.713

[26] Loiseau, M., Lavoué, E., Marty, J. C., \& George, S. (2014). A multiplayer learning game based on mixed reality to enhance awareness on archaeology. EAI Endorsed Transac-tions on Serious Games, 1(3), e3-14. https://doi.org/10.4108/sg.1.3.e3

[27] Srinivasan, R., Boast, R., Furner, J., \& Becvar, K. M. (2009) Digital Museums and Di-verse Cultural Knowledges: Moving Past the Traditional Catalog. The Information So-ciety, 25(4), 265-278. https://doi.org/10.1080/01972240903028714

[28] Bal, M., \& Marx-MacDonald, S. (2002). Travelling concepts in the humanities: A rough guide. University of Toronto Press.

[29] Hornecker, E., \& Stifter, M. (2006, November). Learning from interactive museum in-stallations about interaction design for public settings. In Proceedings of the 18th Australia conference on Computer-Human Interaction: Design: Activities, Artefacts and Environments (pp. 135-142). ACM. 
[30] Marcus, A. S., Stoddard, J. D., \& Woodward, W. W. (2017). Teaching history with museums: Strategies for K-12 social studies. Taylor \& Francis. https://doi.org/10.4324/ 9781315194806

[31] Smith, L. (2016). Changing views? Emotional intelligence, registers of engagement and the museum visit. Museums as Sites of Historical Consciousness: Perspectives on Museum Theory and Practice in Canada, 101-121.

[32] Triantafyllidou, I., Chatzitsakiroglou, A. M., Georgiadou, S., \& Palaigeorgiou, G. (2017, November). FingerTrips on Tangible Augmented 3D Maps for Learning Histo-ry. In Interactive Mobile Communication, Technologies and Learning (pp. 465-476). Springer, Cham.

[33] Muntean, R., Hennessy, K., Antle, A., Rowley, S., Wilson, J., Matkin, B., ... \& Wak-kary, R. (2015, July). Belongings: a tangible interface for intangible cultural heritage. In Proceedings of the Conference on Electronic Visualisation and the Arts (pp. 360-366). British Computer Society.

[34] Price, S., Sakr, M. and Jewitt, C., 2016. Exploring whole-body interaction and design for museums. Interacting with Computers, 28(5), pp.569-583. https://doi.org/10.1093/iwc/ iwv032

[35] Lindgren, R., Tscholl, M., Wang, S., \& Johnson, E. (2016). Enhancing learning and en-gagement through embodied interaction within a mixed reality simulation. Comput-ers \& Education, 95, 174-187 https://doi.org/10.1016/j.compedu.2016.01.001

[36] Malinverni, L., \& Pares, N. (2014). Learning of Abstract Concepts through Full-Body Interaction: A Systematic Review. Educational Technology \& Society, 17 (4), 100-116.

[37] Dede, C. (2009). Immersive interfaces for engagement and learning. Science, 323(5910), 66-69. https://doi.org/10.1126/science.1167311

[38] Lindgren, R., \& Johnson-Glenberg, M. (2013). Emboldened by embodiment: Six pre-cepts for research on embodied learning and mixed reality. Educational Researcher, 42(8), 445452. https://doi.org/10.3102/0013189X13511661

[39] Antle, A. N., \& Wise, A. F. (2013). Getting down to details: Using theories of cogni-tion and learning to inform tangible user interface design. Interacting with Computers, 25(1), 120. https://doi.org/10.1093/iwc/iws007

[40] Pujol, L. and Champion, E., 2012. Evaluating presence in cultural heritage projects. International Journal of Heritage Studies, 18(1), pp.83-102. https://doi.org/10.1080/1352 $\underline{7258.2011 .577796}$

[41] Halverson, E. R., \& Sheridan, K. (2014). The maker movement in education. Harvard Educational Review, 84(4), 495-504. https://doi.org/10.17763/haer.84.4.34j1g68140382063

[42] Mpiladeri, M., Palaigeorgiou, G., \& Lemonidis, C. (2016). Fractangi: A Tangible Learn-ing Environment for Learning about Fractions with an Interactive Number Line. In-ternational Association for Development of the Information Society.

[43] Palaigeorgiou, G., Tsapkini, D., Bratitsis, T., \& Xefteris, S. (2017, November). Embod-ied Learning About Time with Tangible Clocks. In Interactive Mobile Communica-tion, Technologies and Learning (pp. 477-486). Springer, Cham.

[44] Palaigeorgiou, G., \& Pouloulis, C. (2018). Orchestrating tangible music interfaces for inclassroom music learning through a fairy tale: The case of ImproviSchool. Educa-tion and Information Technologies, 23(1), 373-392. https://doi.org/10.1007/s10639-017-9608-Z

[45] Bakker, S., Antle, A. N., \& Van Den Hoven, E. (2012). Embodied metaphors in tangi-ble interaction design. Personal and Ubiquitous Computing, 16(4), 433-449. https://doi.org/10.1007/s00779-011-0410-4

[46] Bailey, D. 2005. Prehistoric figurines. Representation and corporeality in the Neolith-ic. London and NY: Routledge. https://doi.org/10.4324/9780203392454 


\section{Authors}

Stergios Kalpakis is a primary school teacher. After receiving his bachelor at the Department of Primary Education, University of Western Macedonia, Greece, he received his master in Educational Sciences. His research interests include history learning, teaching history with ICT and embodied interactions (kalpakis127@gmail.com).

George Palaigeorgiou is a researcher in the fields of Educational Technology and Human Computer Interaction and he is lecturer in the Department of Primary Education, University of Western Macedonia in Greece, in the field of "ICT in education". $\mathrm{He}$ has extensive teaching experience in several academic departments in the fields of HCI in education, Educational Technology, Computer Science Education, Computer Ethics. His interests include student-computer interactions, embodied learning, mixed reality environments, web 2.0, participatory design, ubiquitous computing, human computer interaction, computer ethics, drones in education (gpalegeo@gmail.com).

Kostas Kasvikis is Assistant Professor of history and culture education in the Department of Primary Education, University of Western Macedonia, Greece. He is also coordinator of the module "Museum education" of the Interuniversity Postgraduate Programme "Museology", Aristotle University of Thessaloniki / University of Western Macedonia. He has served as a primary education teacher for 20 years and has designed educational material and activities for archaeological sites and museums. His research interests and teaching topics are: history didactics, museum education, textbooks research, public archaeology and the politics of the past (kkasvikis@uowm.gr).

Article submitted 12 April 2018. Final acceptance 18 June 2018. Final acceptance 19 June 2018. Final version published as submitted by the authors. 